\title{
BRICOLAGENS ARTÍSTICAS: contradições e (in)conformidades na arte e na educação carioca
}

Renata Rocha

Thamy Lobo

Resumo

O artigo narra as possibilidades criadas com a exposição Pardo é papel de Maxwell Alexandre e os conhecimentossignificacões que permeiam as obras bem como os cotidianos da cidade do Rio de Janeiro, criando um espaço de vida e de mobilização social, possibilitados pelas artes visuais, como modo outro de educação. Populações estigmatizadas ganham espaço e corpo, na referência às personalidades que subverteram os lugares aos quais foram designados na história contada, reescrevendo-as em interlocução com o momento presente, em espaços hegemônicos, como o dos museus. O trabalho docente se reinventa e se desloca no encontro de professores e estudantes com as obras de arte, em um movimento educativo, político e estético de resistência e criação cotidiana.

Palavras-chave: cotidianos; currículos; redes educativas

\section{ARTISTIC DIYS: contradictions and (in)conformities in carioca arte}

\begin{abstract}
This article consists of an essay about the possibilities created with the exhibition Pardo é papel by Maxwell Alexandre. The knowledge-meanings that permeate the artist's works as well as the daily lives of the city of Rio de Janeiro, create a space for life and social mobilization, made possible by culture, especially the visual arts, as another way of education. Stigmatized populations gain space and body, in reference to personalities who subverted the places to which they were assigned and occupy hegemonic spaces. These populations become the works of art stamped in the museum, in a political and aesthetic movement of resistance and daily creation.
\end{abstract}

Keywords: everyday; resumes; educational network

\section{BRICOLAGES ARTÍSTICOS: contradicciones y (no)conformidades en el arte carioca}

Este artículo consiste en un ensayo sobre las posibilidades creadas con la exposición Pardo épapeldel Maxwell Alexandre. Los significados-de-conocimiento que impregnan las obras del artista, así como la vida cotidiana de la ciudad de Río de Janeiro, crean un espacio para la vida y la movilización social, posible gracias a la cultura, especialmente las artes visuales, como otra forma de educación. Las poblaciones estigmatizadas ganan espacio y cuerpo, en referencia a personalidades que subvirtieron los lugares a los que fueron asignados y ocupan espacios hegemónicos. Estas poblaciones se convierten en las obras de arte estampadas en el museo, en un movimiento político y estético de resistencia y creación cotidiana.

Palabras clave: cotidianos; reanuda; redes educativas 


\section{INTRODUÇÃO}

No presente, temos escolhido estudar e pesquisar com a linha dos cotidianos, sobretudo, os escolares e/ou educativos. Sob essa perspectiva, trazemos para este texto as narrativas de estudantes de uma ONG carioca em uma visita ao Museu de Arte do Rio de Janeiro (MAR), com intuito de conhecer a exposição Pardo épapel", do artista plástico Maxwell Alexandre. "Mais do que narrar [...] um tema tão fugidio e fundamental, trata-se de [...] fornecer alguns caminhos possíveis para análises ainda por fazer". (CERTEAU, 2014, p. 35).

A partir dos estudos que temos desenvolvido na corrente de pensamento com os cotidianos, somos levadas a refletir acerca da nossa prática discente na universidade e docente nos espaços educativos em que atuamos, buscando entender como os movimentos políticos e os acontecimentos de origem catastrófica, econômica e/ou sanitária que ocorrem, aparecem nas escolas e nos currículos, sejam eles oficiais ou não. Nesse tocante, indicamos também as possibilidades que a cultura, especialmente a arte plástica, pode auxiliar na invenção de novos currículos e didáticas no trabalho com estudantes, principalmente com jovens de classes populares.

Pensando além da regulação que os currículos conferem aos processos educativos, compartilhamos com as/os leitores uma experiência pedagógica que desafiou aquilo que os museus são conhecidamente: espaço hegemônico de cultura erudita, projetando-os também como espaço de culturas plurais e que podem dialogar com os cotidianos das pessoas comuns.

Este texto, nos limites que tem, narra as compreensões que fazemos de que os conhecimentos são tecidos em redes, dos estudos do/nos/com os cotidianos a partir das referências teóricas, principalmente, em Certeau (2014); da ideia que temos de que a arte aproxima fazeres e saberes; de que os campos disciplinares são contrariados pela rede antidisciplinar que professores e estudantes formam; e que os cotidianos escolares/educativos são locus férteis de epistemologias-políticas-metodologias na criação e circulação de conbecimentossignificações ${ }^{2}$ que subvertem as lógicas hegemônicas.

\section{OS COTIDIANISTAS E AS REDES EDUCATIVAS}

Há algum tempo fazemos a compreensão da total impossibilidade de separar a vida cotidiana - o dia a dia das pessoas comuns — da vida estudantil, sejam essas pessoas, jovens finalizando a etapa escolar na escola básica ou professoras em constante formação, envoltas na dinâmica trabalho-universidade. Todas essas redes educativas que formamos e que também nos formam, compõem nossas subjetividades, bem como nossas inclinações políticas, ideológicas e culturais. Nelas encontramos os pontos comuns que nos unem e também as diferenças que ora agregam, ora separam. Mas que sempre criam uma “[...] multiplicidade de 'táticas' articuladas sobre os 'detalhes' do cotidiano [...]” (CERTEAU, 2014, p. 41).

Nesta corrente de pensamento, com os cotidianos, buscamos referências nos estudos teórico-epistémico-metodológicos de Michel de Certeau e de outros pesquisadores desta linha no Brasil, como Nilda Alves, Inês Barbosa de Oliveira, Carlos Eduardo Ferraço, entre outros. Todos

\footnotetext{
${ }^{1}$ A exposição foi aberta em novembro de 2019 e ficaria até maio de 2020, porém com a pandemia da COVID-19 o museu encerrou temporariamente suas atividades em março de 2020, retornando recentemente a exposição de forma virtual.

${ }^{2}$ Esse termo e tantos outros que ainda aparecerão neste texto, estão assim grafados porque, há muito, percebemos que as dicotomias necessárias à criação das ciências na Modernidade têm significado limites ao que precisamos criar. Com isto, passamos a grafar deste modo os termos de dicotomias herdadas: juntos, em itálico e entre aspas simples.
} 
esses têm suas práticas de pesquisa voltadas para a compreensão dos diversos temas que atravessam a escola, os processos educativos e suas variadas manifestações sociais.

Para este texto, utilizamos a ideia de práticas de espaço pensadas por Certeau (2014) e com isso, se faz necessário explicitar aos leitores, de antemão, as compreensões teóricometodológicas que justificam as escolhas feitas para este texto e agregam algumas maneiras de pesquisar e que inclui modos outros de escrever, de forma a não limitar as compreensões que fazemos, por isso unimos algumas palavras, como acima.

A primeira compreensão é de que o cotidiano é múltiplo e por isso grafamos cotidianos, diferente de Certeau. Para nós, "[...] a grafia no plural busca dar conta da heterogeneidade, da multiplicidade e das singularidades que os constituem." (FERRAÇO, SOARES, ALVES, 2018, p. 90).

Neste pensar (e repensar) as práticas de pesquisas fazemos outra compreensão metodológica importante que altera nossa postura em relação aos cotidianos, de modo que tudo que estudamos, escrevemos, pensamos é feito com os cotidianos e nunca para ou sobre eles. Estamos implicados em todos esses processos que realizamos com as coisas e com as pessoas que perpassam nossos cotidianos.

Estudar e pesquisar com os cotidianos de pessoas comuns, com as histórias comuns que nos são contadas - porque nessas pesquisas as narrativas (todos os sons) e imagens contam - encontrando nestas, sentimentos e conhecimentossignificacões que seus praticantespensantes (OLIVEIRA, 2012) criam, exigiu admitir a riqueza e complexidade desses espacostempos. (ALVES, 2019, p. 19)

Acerca dessa maneira de fazer pesquisa e enxergando essa multiplicidade de operações que os cotidianos nos fornecem para análise, o entendemos como espaçostempos de resistência e criação dos diferentes modos de vida, de educação e de trabalho/pesquisa. Pois somos formados por diferentes redes educativas e em diferentes contextos, como por exemplo: nas redes tecnológicas/sociais, nas redes religiosas, nas redes políticas, no dentrofora das escolas, integramos assim, diferentes redes de criação de conbecimentossignificações e:

[...] de articulação de conhecimentos, de emancipação e de invenção da vida, e não apenas como um domínio do social no qual só existe passividade, submissão, repetição, reprodução e consumo do que é criado em outros contextos (como as políticas educativas oficiais, as disciplinas científicas e o mercado). (FERRAÇO, SOARES, ALVES, 2018, p. 90-91).

Como nos diz Certeau (2014, p. 38), “[...] o cotidiano se inventa com mil maneiras de caça não autorizada", ou seja, não há uma rede disciplinar capaz de modelar indivíduos em conjunto e fazê-los apenas consumidores e/ou usuários dos produtos, sejam eles materiais, artísticos, tecnológicos, sociais, científicos e/ou educativos. Mais ainda, consumidores ou usuários, jogam com as regras e usos estabelecidos para os diferentes bens, adaptando-os às suas necessidades, inclusive recriandoos para o seu uso e consumo.

Por isso, Certeau (2014) rejeita a unilateralidade de colocar para esses usuários o estatuto de dominados, pois eles também criam outras coisas, ao passo que alteram as formas hegemônicas de uso de um dado produto. Essas maneiras de fazer e articular as regras colocadas denota chamá-los de praticantes, segundo o autor, pois não fabricam, contudo, não apenas consomem ou usam. Certeau (2014, p. 17) chamou de táticas, os diferentes usos/funções, empregadas pelos praticantes aos produtos desenvolvidos por quem os fabrica, pois segundo ele: "Embora sejam compostas com os 
vocabulários de línguas recebidas e continuem submetidas a sintaxes prescritas, elas desenham as astúcias de interesses outros e de desejos que não são nem determinados nem captados pelos sistemas onde se desenvolvem".

Rompendo com a ideia de uma suposta regulação vertical dos centros de poder, que imperaria sobre os praticantes/usuários, fazendo-os simples consumidores, desponta os praticantespensantes. Para Oliveira (2012), os/as praticantes, ou seja, as pessoas que compõem e vivem nos cotidianos, são também pensantes, pois formulam outras maneiras de fazer política, de participar da economia, em suma, criam outros modos de viver. Indo além das compreensões de Certeau (2014), a autora chama-os de praticantespensantes.

$\mathrm{Na}$ criação de outros modos de viver, aliam-se também outros modos de perceber e conceber a cultura nos cotidianos. "Mesmo considerando as agendas de liquidação culturais presentes no Brasil e no mundo, pautadas, entre outras coisas, pelas tentativas de normalização, de controle e de destruição da vida [...]" (ALVES, FERRAÇO, GOMES, 2019, p. 1027), os artistas vêm exprimido formas de resistir e enfrentar o desmonte dos canais de cultura e educação, que vem ocorrendo no Brasil desde o fim de 2018. Dentre ações políticas de aniquilação dos projetos culturais, podemos citar o fim da parceria entre o Ministério da Educação (MEC) e a TV escola, que existia desde 1995 e oferecia conteúdo educativo e cultural, o que levou ao fechamento da emissora.

Nas narrativas artísticas expostas nos cotidianos da cidade do Rio de Janeiro, em diferentes espaçostempos artísticos, temos visto o quanto se tem denunciado as mazelas sofridas pela população através da arte, “[...] como possibilidade de não se sucumbir à morte, como alternativa de produção de outros modos de existência" (ALVES, FERRAÇO, GOMES, 2019, p. 1027), a partir da problematização das alteridades e (in) conformidades presentes nos cotidianos periferizados. É bom ressaltar que optamos por áreas periferizadas ao invés de áreas periféricas em concordância com o pensamento de Santos (1993, p. 95-96). Para o autor a urbanização corporativa estabeleceu um modelo específico de centro-periferia, que dentre outras coisas "[...] conduzem à periferização da população mais pobre [...]".

Acerca disso, trazemos a exposição citada anteriormente, para pensar os cotidianos da cidade do Rio de Janeiro e suas marcas e, como diz Certeau (2014), ver como se compõem os "patchworks do cotidiano" e suas múltiplas formas de resistência e a dimensão política e educativa da visita compartilhada entre docentes e discentes a um museu.

\section{BRICOLAGENS ARTÍSTICAS - CRIANDO CONHECIMENTOSSIGNIFICAÇÕES}

A partir das vivências dos moradores das áreas periferiz̧adas, problematizando a cidade falada versus a cidade praticada, o artista idealizador da exposição Pardo é papel tece um tipo de arte peculiarmente fluminense. E, assim, podemos perceber a centralidade da cultura, também, como modo outro de educação nas redes cotidianas das práticas de cidade e seus espaços.

Maxwell, que desenha desde pequeno, defende que "[...] a discussão do que é ser artista é ampla", como disse em entrevista a Marcelo Campos, curador chefe do MAR. De acordo com ele, muitas vezes só são considerados artistas os que possuem formação ou os que conseguem comercializar sua arte. Maxwell começou a produção de suas obras utilizando lixo que era descartado na Pontifícia Universidade Católica (PUC), prestigiada instituição de ensino localizada na cidade do Rio de Janeiro, onde cursou artes plásticas. O papel pardo, hoje seu principal material de trabalho, foi escolhido, a princípio, não por seu teor artístico ou político, mas por ser o material mais abundante na Universidade, já que é muito utilizado por estudantes do curso de moda, na confecção de moldes. 
Depois de um tempo trabalhando com papel pardo, percebeu a sua potência, entendeu a característica apelativa do material e do desígnio de pardo para esconder a negritude. A utilização deste material seria "[...] uma maneira poética de inverter a ordem". (ALEXANDRE, 2020). A escala grande de pintura, emendando vários papéis foi intencional para que literalmente ganhasse espaço nas exposições, já que devido ao tamanho, ocupam grande parte das salas em que são expostas.

Suas obras refletem o empoderamento negro, com abordagem crítica, mas também com afirmações positivas e orgulhosas. Um exemplo é de utilizar em suas obras, tanto nos títulos como em imagens, representantes culturais negros, como rappers, ativistas e artistas em geral; sua intenção é aproximar as áreas periferizadas da arte, através de ícones pops negros conhecidos.

O desejo do artista é ir além das denúncias ao genocídio e precarização das vidas negras. Maxwell traz para a discussão coletiva os estereótipos negros e periferizados presentes no Rio de Janeiro e os aciona para um movimento estético e político de exaltação da diferença, enaltecendo um costume comum carioca, os cabelos tingidos de loiro. Para a inauguração da sua exposição no MAR, foi lançada a ação de "descoloração global de cabelo", um movimento que consistia em reforçar a estética do "preto de cabelo loiro". Para isso, diversas cadeiras foram distribuídas na área externa do museu onde as pessoas estavam presentes, sendo convidadas a descolorir o cabelo. Nessa ação, o público em sua maioria era negro.

Figura 1: Folder divulgando a descoloração global ocorrida na abertura da exposição

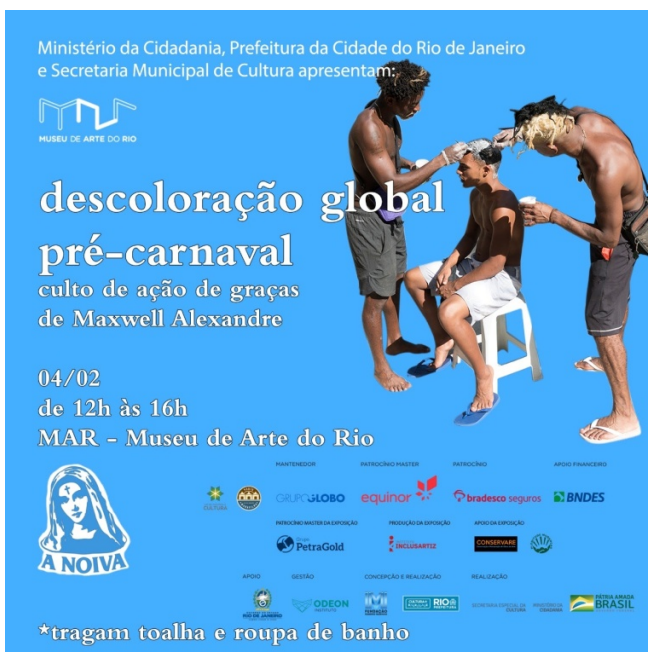

Fonte: Página do Facebook do MAR, 2020.

O objetivo do artista foi alcançado, sem intimidação e hostilidade, ainda que contivesse no folder do evento o título de "Culto de Ação de Graças" e "pré-carnaval", palavras ideologicamente opostas para as redes religiosas. O público se sentiu pertencente ao espaço, que geralmente não é muito convidativo, já que possui diversas camadas objetivas: frequente ausência de negros, vigias, câmeras de segurança, placas solicitando que as obras não sejam tocadas. Segundo Maxwell Alexandre (2020), “[...] preto no topo não é comprar carro e sim entrar no mercado cultural".

As artes plásticas vêm mudando o imaginário, a narrativa e a produção artística fluminense ao trazer à tona o carioca periferizado, seus modos de vida na/com a cidade e seu estilo artístico que é também altamente imagético e que codifica um estilo de arte urbana, política e engajada socialmente com os desafios dos locais de vivência. 
A exposição traz uma crítica social aos estereótipos criados acerca dos moradores ditos de comunidade ou favela e seus modos de vida. Além disso, o artista é morador da Rocinha, que já foi considerada a maior favela da América Latina e desde o ano de 1993 foi transformada em bairro pela Lei n. 1.995/93, o que não significou melhorias para os cotidianos de seus habitantes, tampouco políticas públicas de urbanização para esse local (CIESPI, 2010), localizado na zona Sul do Rio de Janeiro. Como em muitas outras comunidades/favelas do Rio, o poder público chegou fortemente só pelo aparato policial, com a instalação das Unidades de Polícia Pacificadora (UPP).

Figura 2: Obra de Maxwell Alexandre, tinta sobre o papel, simulando o fundo de uma piscina plástica

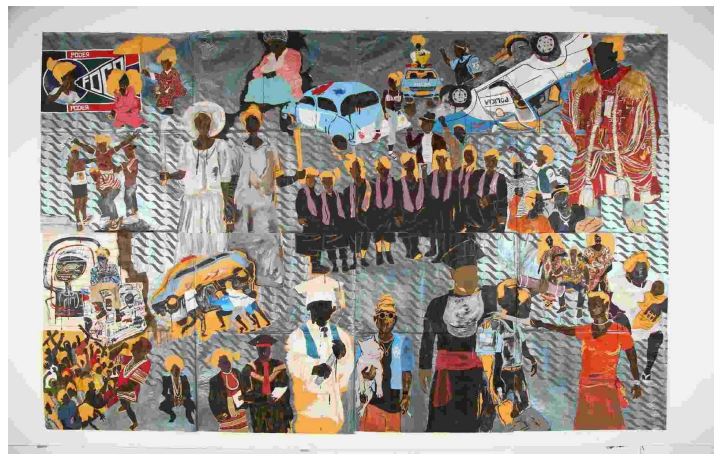

Fonte: Acervo pessoal das autoras. MAR, 2020.

As imagens criadas pelo artista, ora em papel do tipo pardo, ora com material plástico como uma piscina plástica reutilizada (Figura 2) como pano de fundo de algumas obras, remonta às características de lazer no verão das áreas periferizadas da cidade e do estado do Rio, durante a década de 1990. Compreendemos que essa utilização trata da arte dos consumidores de que fala Certeau (2014) pois, segundo o autor, os consumidores se apropriam dos produtos e o reinventam, dando outras funcionalidades e, ao contrário do que muito se pensou em relação a quem fabrica um produto - de que este indicaria o uso, o que seria seguido à risca —, os consumidores atribuem aos produtos a utilização que lhes for mais conveniente.

Figura 3: Policiais e um menino. Fundo com plástico de piscina reutilizado

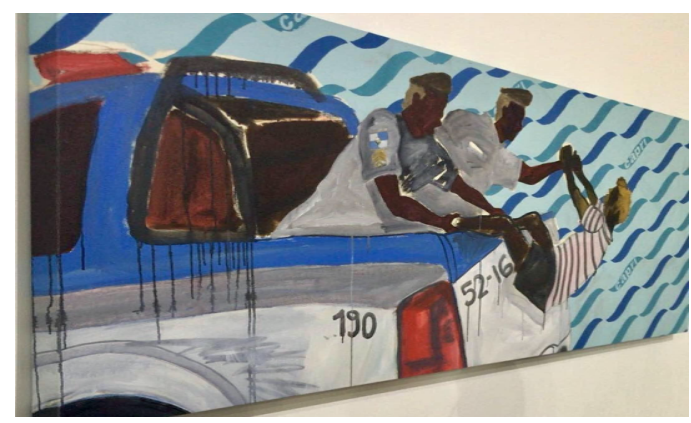

Fonte: Acervo pessoal das autoras. MAR, 2020. 
Uma das possibilidades da imagem acima é a de expressar a relação de dualidade com a qual tem operado a Polícia Militar do Estado do Rio (PMERJ), que “[...] em 2018, foi a mais letal do país, com uma taxa de 8,9 por 100 mil habitantes e com um quantitativo que corresponde a $23 \%$ do total da letalidade policial no Brasil" (MPRJ, 2019). E, se analisados os perfis dos jovens que morrem, são negros e moradores de áreas periferizadas em sua maior parte. A arte denuncia o genocídio que esses jovens negros vêm enfrentando em seus cotidianos, em um espaço artístico hegemônico, como feito no MAR, com esta exposição. A imagem provocou muitos relatos pessoais dos estudantes, que logo narraram experiências violentas pessoais ou conhecidas, com a PMERJ.

Esse modo de criar arte a partir do local de pertença, a que uns chamaram de cultura popular ou marginalidades/arte marginal, Certeau (2014) chama de bricolagens, pois são criações feitas fora do cânone artístico europeu do que é instituído como arte, especialmente pelo tipo de produção artística, combinando diversos elementos dos cotidianos. Supõe que esses: "[...] 'façam uma bricolagem' com e na economia cultural, usando inúmeras e infinitesimais metamorfoses da lei, segundo seus interesses próprios e suas próprias regras. Desta atividade é mister descobrir procedimentos, as bases, os efeitos, as possibilidades". (CERTEAU, 2014, p. 40).

Dessa forma, percebemos que eles criam conhecimentossignificações próprios aos cotidianos periferizados, dando outros usos a objetos como a piscina, citada anteriormente, ou marcando o tipo de arte a partir de sua própria identidade — jovem, negro, usando uniforme da rede municipal de educação - tecendo sua crítica social a partir do local que lhes é próprio, dentro de suas regras e no lugar da cultura dominante - ou que tentam dominar.

Figura 4: Danoninho e Toddynho sendo servidos

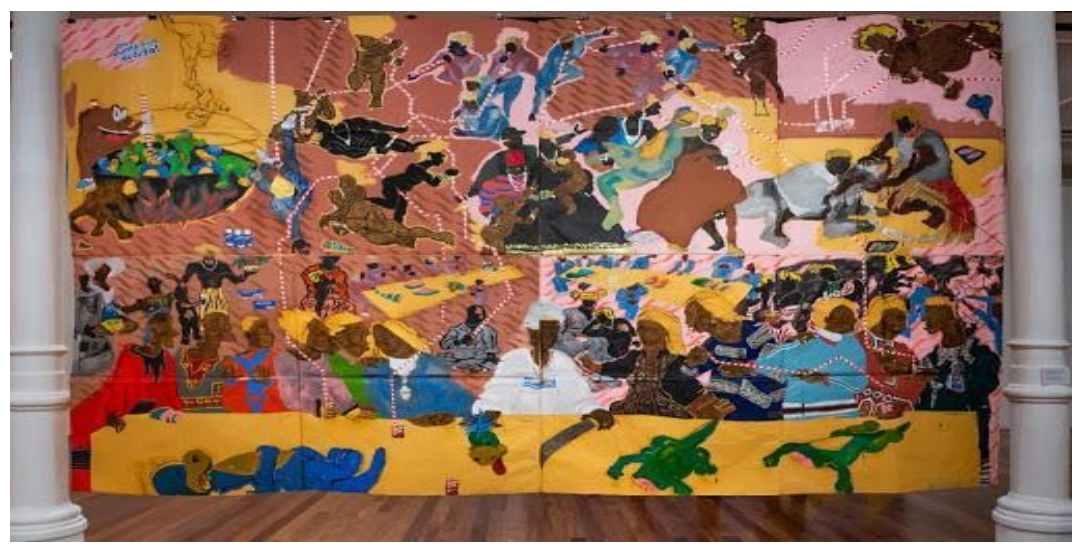

Fonte: Acervo pessoal das autoras. MAR, 2020.

Outra característica nas obras do artista é a problematização do status social embutido numa marca em detrimento de outra, a disputa econômica para além do produto. Podemos observar isso nos símbolos de duas marcas de bebidas conhecidas que permeiam as obras, são elas: o boneco do Toddynho e um dinossauro que representa o Danoninho. Bebidas consumidas por uma parte da população infantil e desejada por outra. Cria categorias de pobre até mesmo entre quem compartilha o mesmo status de favelado, comum a moradores de áreas periferizadas. 
Figura 5: Menino e o Toddynho - poderia ser o artista pela sigla estampada na camisa

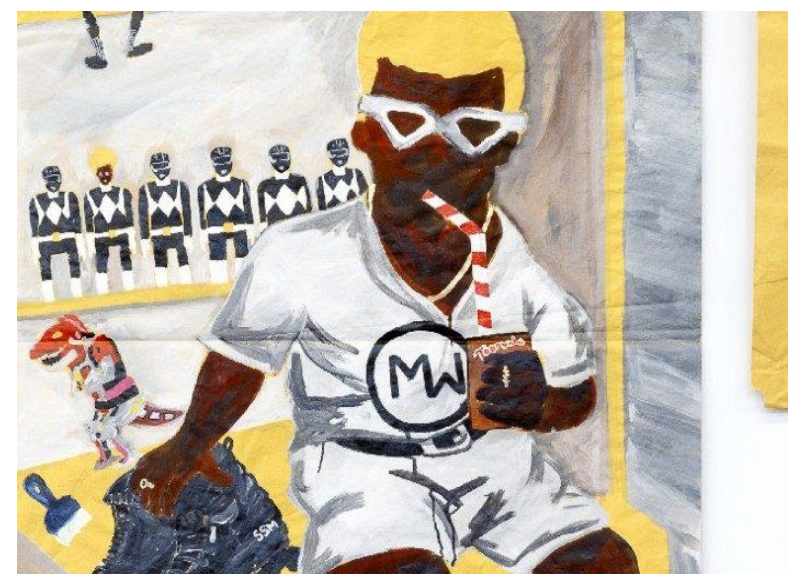

Fonte: Acervo pessoal das autoras. MAR, 2020.

\section{OS PRATICANTESPENSANTES NA/COM A CIDADE PRATICADA - OPÇÕES TEÓRICOMETODOLÓGICAS DE APRENDIZAGENS}

A questão racial é um tema presente em toda a obra de Maxwell Alexandre, assim como a periferização da população negra. $\mathrm{O}$ artista faz uma provocação utilizando um termo polêmico em relação à etnia já no título da sua exposição: Pardo épapel. Frase esta utilizada por alguns movimentos sociais que tratam do conceito de colorismo e querem conscientizar acerca da importância de se autodeclarar negro.

Colorismo significa, de modo resumido, que as discriminações dependem também do tom da pele, da pigmentação de uma pessoa. Mesmo entre pessoas negras ou afrodescendentes, há diferenças no tratamento, vivências e oportunidades, a depender de quão escura é sua pele. Cabelo crespo, formato do nariz, da boca e outras características fenotípicas também podem determinar como as pessoas negras são lidas socialmente. Pessoas negras com tons de pele mais claros, de cabelos menos crespos e/ou traços e contornos mais finos podem passar mais facilmente por pessoas não negras - ou seja, pardas ou morenas - e isso as tornaria mais toleradas em determinados ambientes ou situações; logo, isso influenciaria também no grau de oportunidade entre elas em uma disputa.

É um termo antigo, os primeiros usos da palavra colorismo surgiram nas décadas de $1960 \mathrm{e}$ 1970, notadamente usados nos contextos raciais dos EUA e do Brasil. A autora e ativista negra Alice Walker usou colorismo em uma edição de 1982 da revista Essence para se referir a várias formas de opressão que as mulheres negras enfrentam, definindo o termo em 1983 como o tratamento prejudicial ou preferencial de pessoas da mesma raça baseadas apenas em suas cores.

Apesar do tempo do surgimento, é um termo que tem sido destacado recentemente no Brasil, já que estamos em um momento em que diversos movimentos sociais e ativistas civis denunciam atitudes de preconceito racial, tendo como uma das ações antirracistas, a disseminação de informações acerca de etnia e empoderamento negro. A cada dia percebemos o lançamento de livros com temáticas antirracistas, programas de televisão com debates e informações acerca do tema.

Nas obras de Maxwell, todos os personagens são negros. Alguns títulos fazem referências a títulos de músicas de artistas negros como BK, nome artístico de Abebe Bikila Costa Santos, membro do grupo carioca Nectar Gang, além de retratar ativistas negros da atualidade. Um convite 
a refletir acerca da importância da representatividade, tão necessária às crianças e jovens negros e negras e de pensar uma educação/arte educação, que possa atender os sujeitos periferizados.

Figura 6: Artistas negros

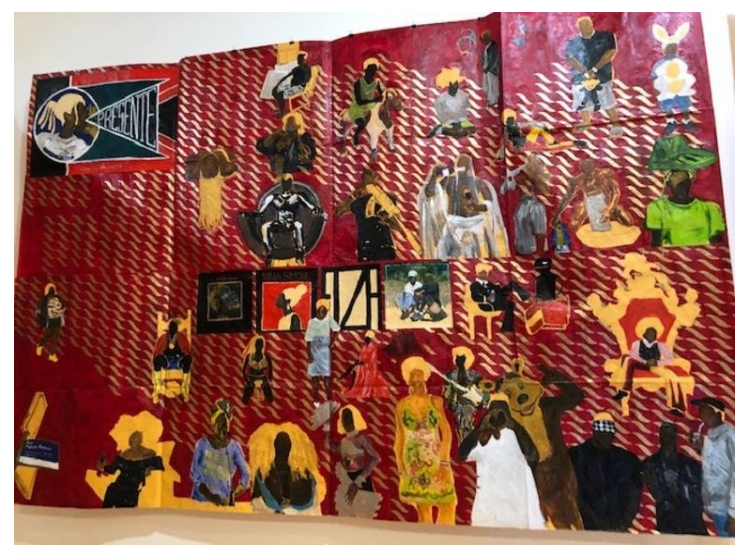

Fonte: Acervo pessoal das autoras. MAR, 2020

Neste tocante, trazemos a exemplo o trabalho formativo desenvolvido em uma organização não governamental (ONG), no Rio de Janeiro. Nesta instituição há um eixo de atendimento a jovens em situação de vulnerabilidade social, em que o objetivo é oferecer um curso de capacitação para inserção no mercado de trabalho. No entanto, os encontros não se restringem a um repasse de informacões e de desenvolvimento de capacidades exclusivamente para o mercado corporativo, mas sim, vivências que possibilitem reflexões acerca dos cotidianos de vida.

A questão racial é tema sempre presente em ações cotidianas da ONG, desde práticas como o preenchimento de uma ficha para se candidatar a uma vaga de emprego em que aparece o item etnia, até nas conversas acerca de notícias atuais, quando frequentemente nos deparamos com matérias que abordam a violência policial, o desemprego, problemas de acesso a atendimento na área da saúde. É frequente o uso de textos e reportagens majoritariamente com personagens/pessoas negros/as neste curso.

As/os jovens atendidos são, em maioria, de cor negra e moradores de áreas periferizadas do município do Rio de Janeiro, que se inscrevem no curso visando à inserção no mercado de trabalho, através do projeto jovem aprendiz, uma forma de contratação de jovens sem experiência de trabalho formal, a partir da Lei da Aprendizagem de 2000, tendo como objetivo capacitar e estimular o emprego. O desejo da maioria, ao iniciar o trabalho formal é o de compor a renda familiar, já que para conseguir a colocação é necessário que a renda familiar seja de até três salários mínimos, por casa. A composição de renda nas famílias abaixo desse perfil de renda é uma necessidade.

As/os jovens são estudantes do primeiro e segundo ano do ensino médio e dividem sua rotina entre a escola regular, geralmente localizada perto de sua residência e o curso de formação, que fica em Vicente de Carvalho, zona Norte do Rio de Janeiro. Os jovens têm, como primeiro desafio, o deslocamento diário, já que o curso acontece cinco vezes por semana.

A formação dura quatro meses, período em que as/os jovens participam de módulos de Comunicação Oral e Escrita, Oficinas de Texto, Iniciação à informática, Ética e Direitos Humanos, Noções administrativas, todos com o objetivo de desenvolvimento para que, além de uma vaga, após o processo seletivo em alguma das empresas conveniadas à ONG, estejam também mais atentas/os aos acontecimentos de seu entorno, se tornem reflexivos e capazes de expressar suas críticas à sociedade. 
Quando as/os jovens precisam responder qual a sua etnia, seja através de um formulário ou de uma pesquisa, muitas/os recorrem aos professores para perguntar a qual etnia pertencem. Uma professora realizou algumas atividades para que as/os jovens refletissem acerca dessa questão, já que a ONG e suas atividades estimulam a curiosidade, pesquisas e questionamentos sobre os temas apresentados pelas/os jovens e pela sociedade, de modo geral.

Figura 7: Giz de cera tons de pele, livro Pequeno Príncipe Preto, espelho e um desenho feito por uma jovem

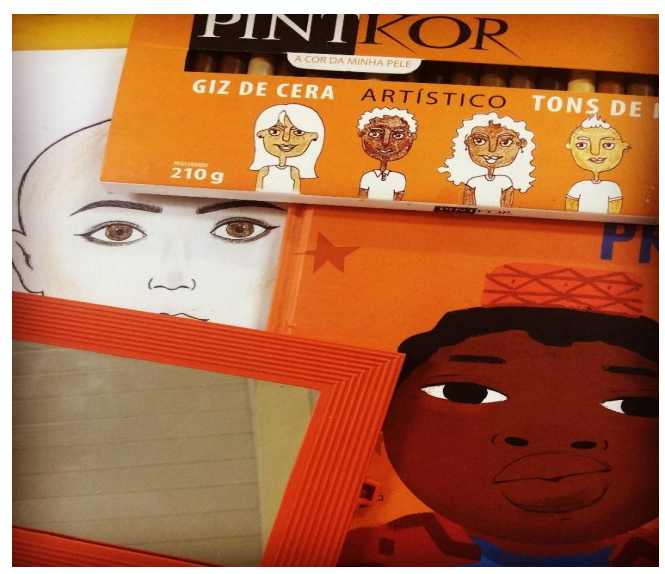

Fonte: Acervo pessoal das autoras. ONG, 2020.

Durante uma atividade, a professora levou uma caixa de giz de cera só com tonalidades de cores de peles - um artefato muito interessante para conversar acerca de etnia- levou também um espelho e o livro recém-lançado Pequeno Príncipe Preto, escrito por Rodrigo França. É um livro infanto-juvenil que faz uma releitura do clássico O Pequeno Príncipe, escrito por Antoine de SaintExupéry. Além do livro, a professora levou diversas revistas de ampla divulgação comercial do mês de março de 2020 cujas capas eram compostas por personalidades negras. O grupo conversou acerca de representatividade, do colorismo, apresentaram narrativas de questões raciais que permeavam suas famílias, questionaram a etnia inserida em suas certidões de nascimento, falaram acerca de racismo estrutural e da falácia do racismo inverso.

Ao final, foi solicitado que fizessem um autorretrato de seus rostos, depois deveriam se olhar no espelho e colorir com a cor da pele que se viam ou que se sentiam pertencentes. Após esta dinâmica, muitos estudantes repensaram em que lugar marcariam o $X$ na opção de etnia da ficha. As conversas e narrativas pessoais tornaram os encontros mais significativos no trabalho com um tema importante à sociedade, como é a temática racial. Entendemos que o convite às narrativas de experiências e/ou percepções de vida é uma estratégia didática que humaniza a aula conteudista e aligeirada, como muitas vezes acabam sendo. Para Serpa (2018, p. 101):

Podemos contar ou descrever uma vivência, um fato, um acontecimento. Mas quando narramos uma experiência, convidamos outros seres humanos a compartilharem conosco de nossa humanidade. Narrar uma experiência é abrirse ao encontro e, talvez, seja exatamente este encontro que percamos na troca diária e desesperada de milhares de informações, tantas vezes inúteis. 
Figura 8: Autorretrato feito por uma jovem

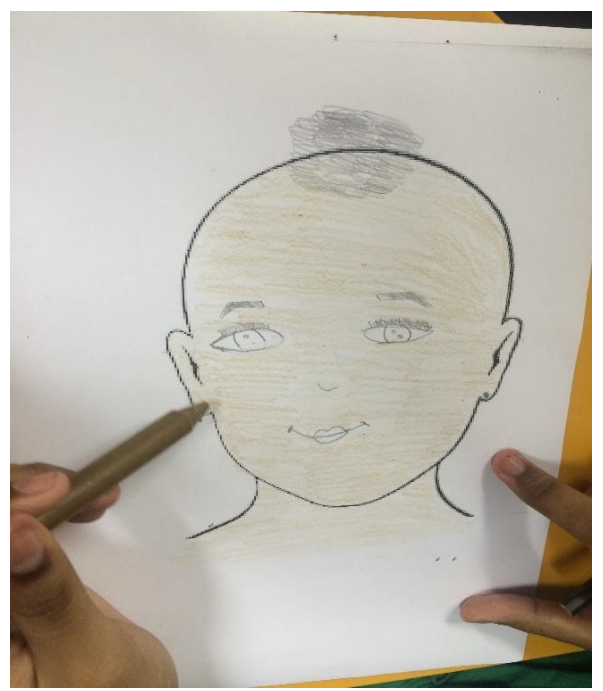

Fonte: Acervo pessoal das autoras. ONG, 2020.

Continuando a atividade iniciada na ONG, o grupo de jovens teve a oportunidade de uma visita guiada à exposição Pardo épapel. A visita aos espaços culturais é muito estimulada, pois as/os professores acreditam que as/os jovens precisam ter consciência de que elas/eles pertencem a todos os espaços da cidade e viver a cidade é um direito deles. Muitas vezes ao adentrarem museus e centros culturais, escutamos das/dos estudantes questionamentos voltados a dúvidas se aqueles lugares estarão abertos para visitas não educativas, se podem frequentá-los em outras oportunidades, com amigos ou familiares. Percebemos que é difícil se considerar pertencente a um espaço que só lhe foi apresentado através de livros, sites ou em visitas educativas. É um exercício estimular os/as estudantes a frequentar exposições, explorar a cidade e praticá-la.

Os trajetos até os lugares das exposições já são aprendizados, principalmente tratando-se de estudantes que em breve farão longos caminhos de sua residência para o futuro emprego, pois a maioria das/dos jovens reside na zona oeste e norte da cidade do Rio de Janeiro e boa parte das empresas conveniadas e que contratam jovens da ONG, estão localizadas no Centro da cidade, o que demandará delas/deles, um conhecimento de como chegar da melhor maneira, ou seja, mais rápida, ao seu local de trabalho. Sendo assim as/os professores costumam marcar com as/os jovens já nos lugares de visita cultural, tendo o cuidado e carinho de formar grupos para irem juntos e, também, repassar todas as informações possíveis para auxiliar o trajeto. É muito interessante os seus relatos, de como é a experiência de andar pela primeira vez de metrô, de conseguir chegar ao Centro sem os pais e de caminhar entre os prédios altos.

$\mathrm{Na}$ visita ao MAR, ao adentrar na exposição Pardo épapel, as/os jovens logo apontaram as semelhanças entre suas moradias e as retratadas, admiravam os títulos de músicas, especialmente ao dos rappers que ouviam presentes nas obras. Contavam histórias acerca do Caveirão, nome popular do carro blindado usado pela PMERJ em incursões nas áreas de risco, geralmente em favelas, presente nas imagens e admiravam a técnica simples e possível, utilizada pelo artista. Reconheceram-se, a partir da arte exposta. Fazendo-nos, mais uma vez, concordar com Certeau (2014) quando diz que "[...] só há lugar quando frequentado por espíritos múltiplos [...]". Percebemos assim a cultura como identificação e apropriação, e os espaços a soma dessas multiplicidades, o que torna um lugar como habitável. Na apresentação do livro $A$ Cultura no plural, Luce Giard, deixa clara a visão de Certeau acerca da cultura, quando diz que: 
Sob a perspectiva de Certeau, toda cultura requer uma atividade, um modo de apropriação, uma adoção e uma transformação pessoais, um intercâmbio instaurado em um grupo social. É exatamente esse tipo de "culturação", se assim podemos dizer, que confere a cada época sua fisionomia própria. (CERTEAU, 2012, p. 10)

Diversos aspectos da exposição foram explorados e comentados pelas/pelos jovens que contaram com dois mediadores muito atenciosos que tiveram o cuidado de não interferir nas interpretações ou comentários, mas sim ampliar com algumas informações técnicas necessárias, além de instigar as/os jovens a prestarem atenção aos detalhes.

Representatividade foi a palavra que expressou a visita daquela tarde, a cada papel pardo exposto, diversos comentários acerca das referências utilizadas e de lembranças de suas áreas periferizadas. As/os jovens perguntavam, a todo o momento, se o que estava à frente delas/deles seria arte, como se a arte fosse algo abstrato, de difícil interpretação e impossível identificação por pessoas comuns. As histórias de vida se misturaram às obras de arte de Maxwell, forjando novos aprendizados em um currículo praticado.

Ao final da visita, as/os jovens e a professora sentaram no espaço externo do Museu e conversaram acerca de representatividade, etnia e empoderamento. Um deles disse que "[...] não imaginava que a dúvida em que lugar marcar o $X$, lhe traria tantas inquietações e reflexões". Compreendendo assim o papel da arte ou daquela arte específica, que para um grupo de jovens periferizados refletiu em tanta potência e reconhecimento.

Ao entrar no Museu, outro/a jovem observou que era o único grupo de negros no local. Após a visita a exposição, ele reiterou: "Somos os únicos negros aqui, mas o autor da exposição é negro. Um negro que está expondo!”. Há contradições e (in)conformidades nos cotidianos. Como disse o curador da exposição e o diretor do MAR:

Porém, aqui, o pardo é ressignificado pelo artista, nos levando a outras direções. Ao produzir autorretratos sobre papel pardo, MW (assinatura do artista) passa a perceber que estava, também, diante de um ato político: pintar corpos negros sobre papel pardo. Os estigmas são assumidos e revertidos. A cor da pele negra, confundida com a cor do papel, retorna como condição de resistência, como reação: "pardo é papel". Congregam-se, assim, arte e cultura, forma e subjetividade. (Carlos Gradim - diretor-presidente do Instituto Odeon, Marcelo Campos - curador associado do MAR).

Podemos enxergar, nos diferentes contextos cotidianos, modos outros de educação, praticando o espaço do museu e da cidade como possibilidades outras de criar conbecimentossignificações e, também, verouvirsentirpensar dos praticantespensantes e a relação estabelecida com a cidade que praticam. "Praticar o espaço [...] é, no lugar, ser outro e passar ao outro" (CERTEAU, 2014, p. 177, grifo no original), na troca que o espaço da arte oferece aos diferentes sujeitos das cidades. Em meio às contradições, criando táticas de resistência para expressar sua inconformidade com o lugar, sobretudo, para resistir às "políticas de morte" e inventar possibilidades outras de vida e "[...] cria na cidade planejada uma cidade 'metafórica' ou em deslocamento [...]" (CERTEAU, 2014, p. 177). Criando com a arte conbecimentossignificações políticos, estéticos e de resistência cotidiana. 


\section{CONCLUSÃO}

Os processos de escolarização foram formulados com base na invisibilização de grupos de pessoas, sobretudo negras e indígenas. A organização hierárquica das disciplinas nos currículos, que levou a contagem linear da História do mundo e das coisas, centralizada e/ou oriunda da Europa repercute até hoje nos modos pelos quais os currículos oficiais são pensados. As Ciências Modernas indicaram as disciplinas que mereciam destaque na escola, elegendo primeiro a Matemática e consecutivamente a língua materna, como as mais importantes e que devem ser investido maior tempo - o que ocorre até o presente. Já disciplinas como História ganhou valor menor e contada pelos colonizadores. O modo de narrar e fazer a ciência e a pesquisa científica também não é aceito, em algumas linhas de estudo, se não estiverem adequadas ao que os centros hegemônicos determinam.

Em espaços de educação não formal, como a ONG, vemos, frequentemente, a mesma lógica se infiltrar sempre justificada pela demanda do mercado. Neste caso, o mercado de emprego, do qual todos necessitamos. Os campos de formação que subsidiam o ingresso em uma "boa empresa", estão ligados à matemática e ao ensino formal da língua materna, nas chamadas "Oficinas de texto", mantendo as características históricas que conferiram destaque a algumas disciplinas do currículo formal oficial. Se de um lado o foco do trabalho está voltado ao atendimento às/aos “jovens em situação de vulnerabilidade social”, de outro eles precisam de alguma maneira se enquadrar às regras prescritas de mercado.

Em contrapartida, disciplinas como artes e educação física são desvalorizadas e tem menor espaço nos currículos, ainda que hoje já reconheçamos a importância vital da arte e a necessidade da prática de atividades físicas para o corpo e para a mente. As aulas de campo/aulas-passeio recebem cada vez menor investimento - elas são custos que tendem a ser evitados pelas instituições, ainda que ninguém negue a importância que ela agrega, poucos são os que ousam defender. $\mathrm{O}$ deslocamento é ruim, o trânsito caótico, a violência urbana é grande, a exposição tem longas filas, os estudantes "[...] só querem passear e não prestam atenção" e por aí vai.

O currículo oficial enxuga a liberdade e as subjetividades em prol da regulação e manutenção dos valores empregados às disciplinas eleitas. Até quando ele reconhece que parte dos povos originários do Brasil e vitais na construção da sociedade brasileira foram silenciados historicamente e indica, através da lei, como é o caso da Lei n. 11.645, as Diretrizes para o Ensino da História e Culturas africanas, Afro-brasileiras e Indígenas. O documento orienta que a temática seja tratada especialmente nas disciplinas de Artes, Literatura e História, evitando recontar a História do mundo também com os olhares dessas populações nos saberes eleitos principais ou fundantes da ciência. Não acatando como legítimas os conhecimentos da Etnomatemática ou conhecimentos medicinais dos povos indígenas, por exemplo. Mas o revés disso, temos a linha de estudos teóricometodológicos com os cotidianos e "Nesse sentido, assumir essas noções como lógica dos cotidianos implica a inutilidade operatória das dicotomias para se compreender como são criados os conhecimentos e as estéticas de existência". (FERRAÇO, SOARES, ALVES, 2018, p. 98).

O currículo praticado por sua vez foge de toda previsibilidade e controle, para criar táticas a partir do que os cotidianos nos requisitam. Eles são tecidos cotidianamente, em redes, por estudantes e professores em diferentes espaçostempos. "Nas pesquisas com os cotidianos partimos da ideia de que pensar as práticas cotidianas de viver dentro e para além das macronegociações políticas e econômicas permite nos aproximar da complexidade da vida sem abrir mão de todas as redes que formamos e nas quais nos formamos". (ALVES et al, 2019, p. 19). 
Dessa maneira entendemos os currículos como articuladores de ideias e políticas cotidianas no enfrentamento a problemas sociais e as experiências educativas/escolares que tentam regular o trabalho docente. Sendo fundamental a politização e potencialização dos currículos, em conjunto com docentes e discentes das tantas redes educativas. Entendendo que os conhecimentos acontecem no dentrofora das instituições, sendo impossível sua separação e/ou categorização. Os aprendizados se estabelecem na troca e na cooperação entre pessoas, nos encontros em uma ONG e na visita a exposições artísticas.

O que é fundamental na relação de aprendizagem para nós, cotidianistas, é ter a convicção primeira de que todos ensinam e aprendem e, em segundo lugar, é que devemos assumir a responsabilidade de criar possibilidades para que o que é aprendidoensinado acolha e pluralize mundos e ideias, desfaça mitos, preconceitos e democratize as formas de conhecer, aprenderensinar e fazer com os cotidianos.

\section{REFERÊNCIAS}

ALVES, Nilda; ANDRADE, Nivea; CALDAS, Alessandra. Os movimentos necessários às pesquisas com os cotidianos, após muitas 'conversas' acerca deles. In: OLIVEIRA, Inês Barbosa de; PEIXOTO, Leonardo Ferreira; SÜSSEKIND, Maria Luiza (orgs.). Estudos do cotidiano, curriculo e formação docente: questões metodológicas, políticas e epistemológicas. Curitiba: CRV Ed., 2019. p. $19-45$.

ALVES, Nilda; FERRAÇO, Carlos Eduardo; GOMES, Marco Antonio Oliva. Os cotidianos espaçostempos de resistência e criação. Currículo sem Fronteiras, v. 19, n. 3, p. 1026-1038, set./dez., 2019.

BIOGRAFIA BK. Disponível em https://www.last.fm/pt/music/BK/+wiki. Acesso em 2 jul. 2020.

CERTEAU, Michel de. A cultura no plural. Campinas, São Paulo: Papirus, 2012.

CERTEAU, Michel de. A Invenção do cotidiano 1. Artes de fazer. 4. ed. Trad. Ephraim Ferreira Alves. Petrópolis: Vozes, 2014.

CIESPI. Centro Internacional de Estudos e Pesquisas sobre a Infância. PUC/Rio. Cartografia. Disponível em http://www.ciespi.org.br/Cartografia/Historico-Rocinha-1038. Acesso em 14 de mar. 2019.

ENTREVISTA ALEXANDRE MAXWELL. Disponível em https://www.instagram.com/museudeartedorio/?hl=pt-br. Acesso em 11 ago. 2020.

FERRAÇO, Carlos Eduardo; SOARES, Maria da Conceição S.; ALVES, Nilda. Michel de Certeau e as pesquisas nos/dos/com os cotidianos em educação. Rio de Janeiro: EdUERJ, 2018.

MPRJ. Ministério Público do Rio de janeiro. MPRJ apura o aumento dos indices de letalidade policial no Estado do Rio por meio de inquérito civil. Disponível em http://www.mpri.mp.br/noticias-todas/$\angle$ detalhe-noticia/visualizar/77201?p p state $=$ maxi mized. Acesso em 10 jul. 2020.

PARDO É PAPEL. Disponível em http://museudeartedorio.org.br/programacao/pardo-epapel/. Acesso em 10 ago. 2020.

SANTOS, Milton. Urbanização brasileira. São Paulo: Hucitec, 1993.

SERPA, Andréa et al. (orgs.). Conversa como metodologia de pesquisa: por que não? Conversas: possibilidades de pesquisas com os cotidianos. Rio de Janeiro: Ayvu, 2018. 


\section{Informações das autoras}

Renata Rocha de Oliveira

Mestranda no PPGEDU/UERJ

E-mail: renatarochaoliveira87@gmail.com

ORCID: https://orcid.org/0000-0003-2160-2302

Link Lattes: http://lattes.cnpq.br/6367916420672373

Thamy Lobo

Mestranda no PPGEDU/UERJ

E-mail: thamy.lobo@hotmail.com

ORCID: https://orcid.org/0000-0002-2606-9642

Link Lattes: http://lattes.cnpq.br/3645868616018035 